\title{
PHYSIOTHERAPY IN THE MANAGEMENT OF THE STABBED CHEST
}

\author{
Ann Fairlie B.Sc. Physiotherapy (Witwatersrand)
}

\begin{abstract}
The role of physiotherapy in the management of the surgical patient is playing an ever increasing role. A short comparative study was conducted at Non-European Hospital, Johannesburg in which two groups of randomly selected patients acimitted with stabbed chests and hacmopneumothoraces were studied.

The lirst group was managed in the usual manner, that is the patient was resuscitated, an intercostal drain was insarled and some form of physiotherapy was given the next day. some 12-18 hours after the intercostal drain hal been inserted.

The second group was managed similarly except a nandardised routine of physiotherapy was instituted 1MMEDIATELY after inscrtion of the intercostal drain.

The paticnts were then studied using the following parametcrs.
\end{abstract}

\section{Vitalograph Studies:}

The vitalograph is a portable instrument designed for a single breath test which is graphically recorded and from which parameters of ventilatory function can be measured and calculated. Figure 1 shows the vitalograph in use.

The following lung capacities were compared:-(a) Forced Vital Capacity (FVC).

(b) Forced Expiratory Volume (FEV).

(c) Maximum Voluntary Ventilation (MVV). These observations were made 12 hours after removal of the intercostal drains in both groups.

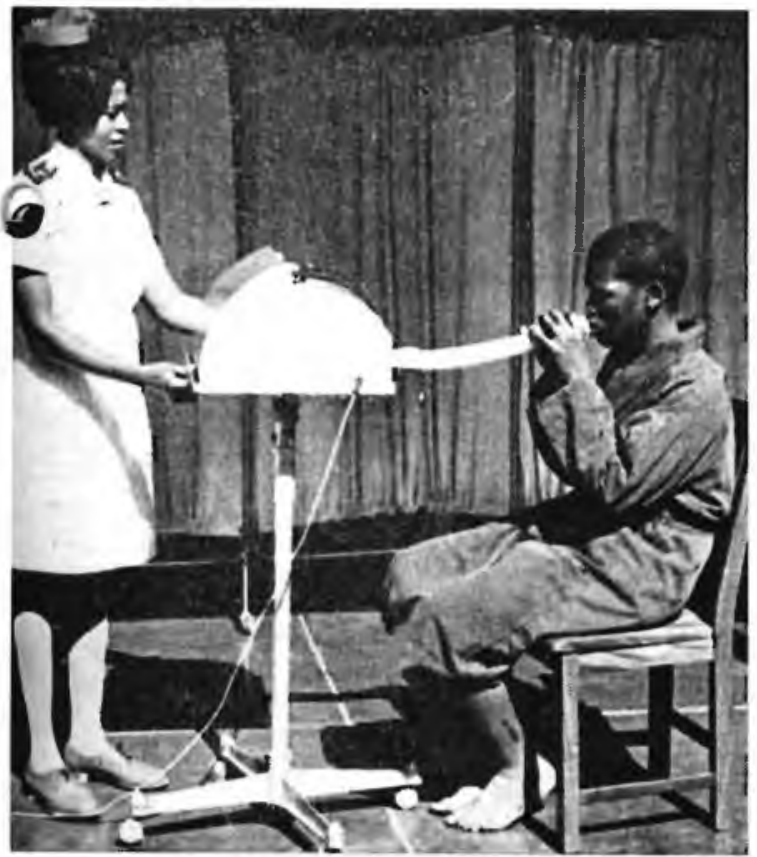

2. Duration of Intercostal Drainage.

3. Duration of Hospitalisation.

4. Incidence of Temperatures.

5. Radiological Resolution.

Results showed a distinct improvement in the group receiving inmediate early physiotherapy.

\section{RESULTS OF SURVEY:}

1. Vitalograph:

In only the MVV parameter was there a significant difference between the two groups.

In the group receiving early physiotherapy there was a mean MVV of $40,4 \%$ of the expected norm value.

In the untreated group this value was $31,8 \%$ of the expected norm.

2. Duration of Imercostal Drain Drainage:

Average duration for the treated group was 1,50 days.

In the untreated group drainage duration was 2,77 days.

3. Time of Hospitalisation:

Treated group 2,5 days.

Untreated group 4,1 days.

4. Incidence of Temperatures:

In the treated group, 2 out of the 12 patients developed temperatures in excess of $99^{\circ} \mathrm{F}$. In both these cascs the pyrexia lasted less than 8 bours. In the untreated group, 8 out of the 9 patients developed temperatures in excess of $99^{\circ} \mathrm{F}$.

5. Radiological Resolution:

In the untreated group, 2 patients developed radiologically confirmed pneumonic consolidation.

As a means of comparison, radiological resolution did not prove to be a reliable parameter as certain criteria are laid down before discharge of the patient may occur. One of these criteria is adequate radiological resolution of the haemo-pneumothorax. These results clearly show benefit in those patients treated by early physiotherapy, and suggest that a surgical unit managing this type of injury should have a resident Physiotherapist at all times.

The aims of the Physiotherapy and the programme used is set out below.

\section{THE FORMAT OF PHYSIOTHERAPY WAS STANDARDISED AND THE FOLLOWING AIMS AND METHODS WERE USED:}

1. PHYSIOTHERAPY TO INCREASE INTRAPLEURAL PRESSURE:

(i) The normal intra-pleural pressure is slightly negative. Any form of val salva manoeuvre would tend to increase this intra-pleural pres- 


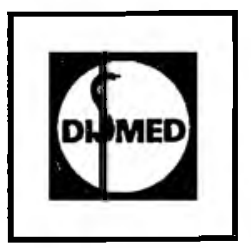

\section{THE \\ PRESENTS - Minidyne mk III \\ TRANSISTORISED FARADIC UNIT}

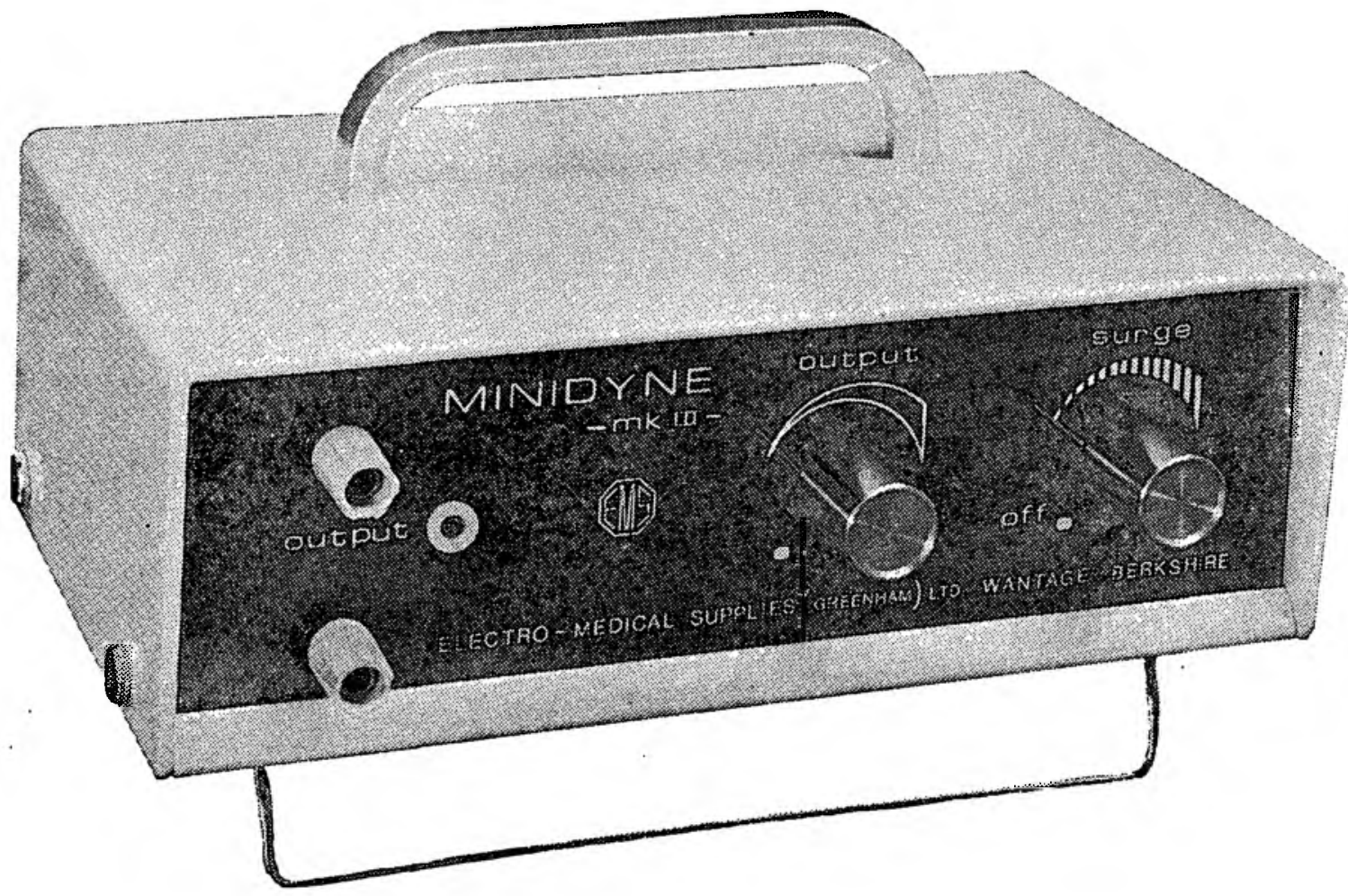

Representing another advance in the evolution of the Minidyne, the Mark III version incorporates printed circuits which reduce the size but also enhance the reliability; continuing features are

wide range of surge speed control with output sufficient for all forms of faradic techniques

audible as well as visual indication of surge speed enabling the operator to anticipate a muscle reaction without having to watch the control panel

fitted with Ever Ready PP9 batteries which will give up to six months' use without replacement and are obtainable worldwide

WEIGHT reduced to: $4 \mathrm{lbs}$. $(1,8 \mathrm{~kg})$

SIZE reduced to 8 " $\times 5 \frac{1}{2} " \times 2 \frac{1}{2} "(20 \mathrm{~cm} \times 13,5 \mathrm{~cm} \times 6 \mathrm{~cm})$.

PRICE:

$\mathbf{R 8 7 , 5 0}$

complete with accessories.

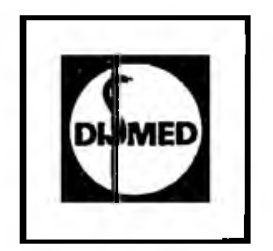

\section{MEDICAL DISTRIBUTORS PDNAS BPK $_{\text {PT }}^{\text {PTD }}$}

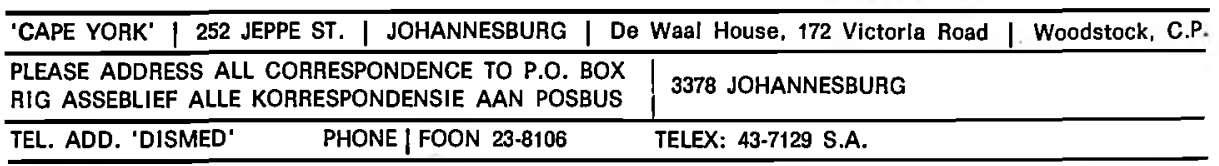


sure and this increased intra-pleural pressure would obviously facilitate drainage of any of the abnormal contents in the intra-pleural space resulting from a stab wound. This facilitated drainage would naturally occur through the intercostal drain.

An ideal method to increase intra-pleural pressure had to be found which was simple, would occupy the patient's attention and concentration and thereby distract his attention from any resulting pain.

In this study the patients were asked to blow up a number of coloured balloons. Their attention was focused on the colours and degrees of difficulty that each balloon's difference represented. They were often set the challenge of inflating a large number of balloons.

This simple manoeuvre fulfilled the above criteria admirably and large quantities of air and blood were noted to drain during this procedure which basically is a simply modified val salva manoeuvre.

As soon as full drainage from the intra-pleural space had occurred full lung expansion became possible and was facilitated by the following exercises.

(ii) General deep breathing exercises are done in order to achieve maximum inspiration and expiration. The patient is instructed to blow at a tissue or coloured streamers as hard and as long as possible. After every blow the tissue can be moved further away from the patient so that his breath may reach the tissue. This increases the intra-pleural pressure thereby facilitating drainage and expansion of the lung.

Unilateral and posterior basal breathing exercises to the affected side and bilateral lateral costal breathing exercises are taught to the patient with a good explanation as to why he must use that side. By concentrating on the affected side, the patient will then be able to assist in re-expanding this collapsed area.

(iii) Coughing is interspersed regularly between the exercises. The patient is taught to cough, i.e. right from the bottom of his chest and not just to make noises in his throat and to expectorate any secretions if present. This increases the intra-pleural pressure and aids drainage as well as getting rid of any secretions that may be present in the lungs and bronchial tree.

\section{PHYSIOTHERAPY TO FACILITATE}

\section{DRAINAGE:} effects:-

Trunk exercises have a number of beneficial

(a) By trunk motivation the patient twists from side to side and in doing so the patient expands and contracts each hemithorax alternately. This manoeuvre assists re-expansion and thus the expanding lung forces out intrapleural fluid, i.e. drainage is facilitated.

(b) Trunk exercises are also associated with gross alterations in posture and these are achieved by a few simple exercises which follow. Changes in posture tend to move the intrapleural contents towards the site of the drain.

\section{Exercises Used:}

Sitting; Arms bend, opposite elbow to touch opposite knee with trunk rotation.

Sitting; Arms at sides, trunk flexion to both sides so that hand touches fioor on that side.
Sitting; Arms reach, loose arm and trunk swinging from side to side.

Standing Arms to stretch position then bend down and/or to touch floor with hands, keeping the Sitting; knees straight and back up again to extension position with arms to stretch position.

Standing; Arms yard; bend and touch left foot with right hand then up to starting position. Repeat - touch right foot with left hand.

There are many more variations of trunk exercises but it is best to keep to a few simple exercises which can be mastered without much difficulty by the Non-European. There are many other reasons for keeping to the some routine exercises.

These patients are not in hospital for a long period so they do not have time to get bored with the same exercises than variations which they find difficult to master.

It is also essential that they do these exercises correctly in order to fulfill the above aim and therefore a large amount of valuable time especially in the immediate treatments would be wasted in correcting a large variety of exercises.

\section{PHYSIOTHERAPY TO PREVENT ACCUMULA-} TION OF SECRETIONS IN LUNGS:

Coughing and breathing exercises are done in order that this aim may be fulfilled and these exercises have already been described in Method 1(ii) and (iii).

If a large amount of secretions have accumulated in the lungs and bronchial tree postural drainage should be done.

\section{PHYSIOTHERAPY TO INCREASE LUNG} PERFUSION:

Strongly motivated general body exercises such as running on the spot, jumping to stride position and back again from the standing position, and squats (i.e. knees bend to full flexion and then extension), increase the respiratory rate, the pulse rate and the ventilatory minute volumes. These exercises should be done until the pulse is approximately 140 beats per minute, and this increases lung perfusion and ventilation. Both these factors tend to decrease the existing atelectasis and facilitate resolution. Purely on a prophylactic basis atelectasis is also prevented.

The movement of the body moves the fluid inside the chest around and drainage is also assisted.

If the patient is unwilling to do many of these above agility exercises it is necessary for the Physiotherapist to carry the drip, and the patient to carry the underwater drainage bottle. The patient should then be marched up and down the ward at a fast pace.

\section{PHYSIOTHERAPY TO PREVENT POSTURAL DEFORMITIES:}

The posture of the patient is corrected, if necessary, in sitting and standing. The usual deformity adopted is a high shoulder on the affected side which is corrected by instructing the patient to push that arm towards the ground and splinting of the arm and chest wall is corrected with special arm and shoulder exercises plus the trunk exercises with associated arm movements as already mentioned. Whenever correcting posture the ideal method is for there to be a mirror in front of the patient so that he may see his deformity and so be able to correct it. 


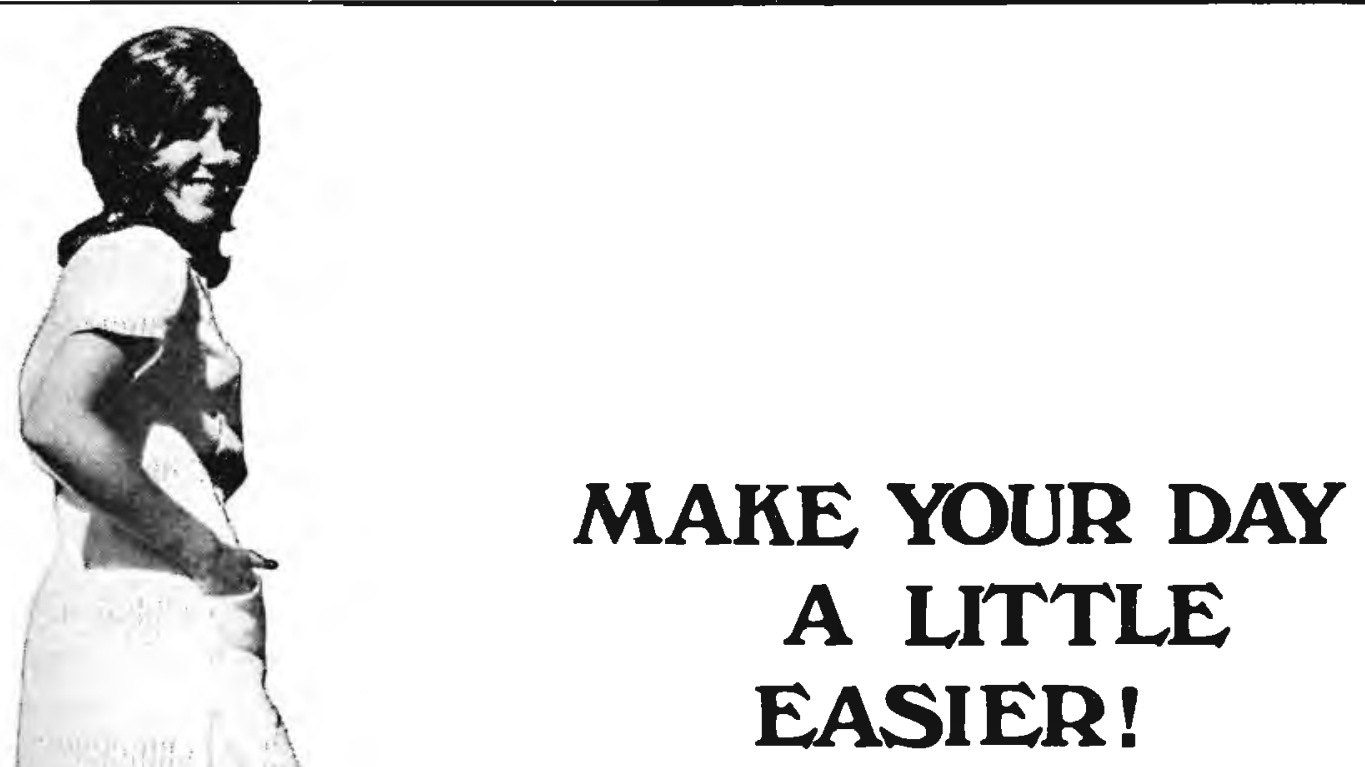

You physios are a hard-worked group, we know. In the day's work, environment and comfort become more and more important - and while there's not much we can do to help fix the background in which you work, you'll find a comfy, practical working rig in the new specialpurpose uniform we ve designed with you in mind.

It's a continental style dress, with Bermuda-type shorts to match. A side vent in the skirt and the generous cut, mean that you'll work more easily, and feel comfortable right through the hard day.

Your option of short or long sleeves, in drip-dry, hard-wearing fabric... white or saxe blue. Sizes 32 to 42 .

Elegance and efficiency ... what more could you ask?

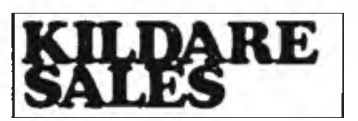

4th Floor, Pritchard House, 83 Pritchard Street, JOHANNESBURG. Tclephone 23-4405.

87 Marion Avenue, Glenashley, DURBAN. Telephone 83-7226.

Fully illustrated catalogues and price lists of our full range are available free to you. Just drop us a postcard (P.O. Box 752, Johannesburg) or telephone 23-4405 any time, including nights, weekends and holidays. We're also happy to execute phone orders, of course. 
Arn and shoulder exereises being:-

Sitting; Arms bend, elbow circling.

Sitting; Hands clasped in front, streach up above head then put hands behind neck keepins elbows well back (so external rotation at the shoulder joint occurs) to up above head again and down.

More emphasis is laid in the later treatments on the correction of any postural deformity that may have occurred, but these should not result if adequately corrected in the early treatments.

NOTE:

(1) Most of the patients are under the influence of alcohol when admitted and so the Physiotherapist has to use cvery means of getting the patients full attention and co-operation which plays so important a part in the effectiveness of the treatment. The Physiotherapist must have a rather aggressive approach in order to fulfill the aims of her treatment. These patients are usually young and are fit enough evcn after

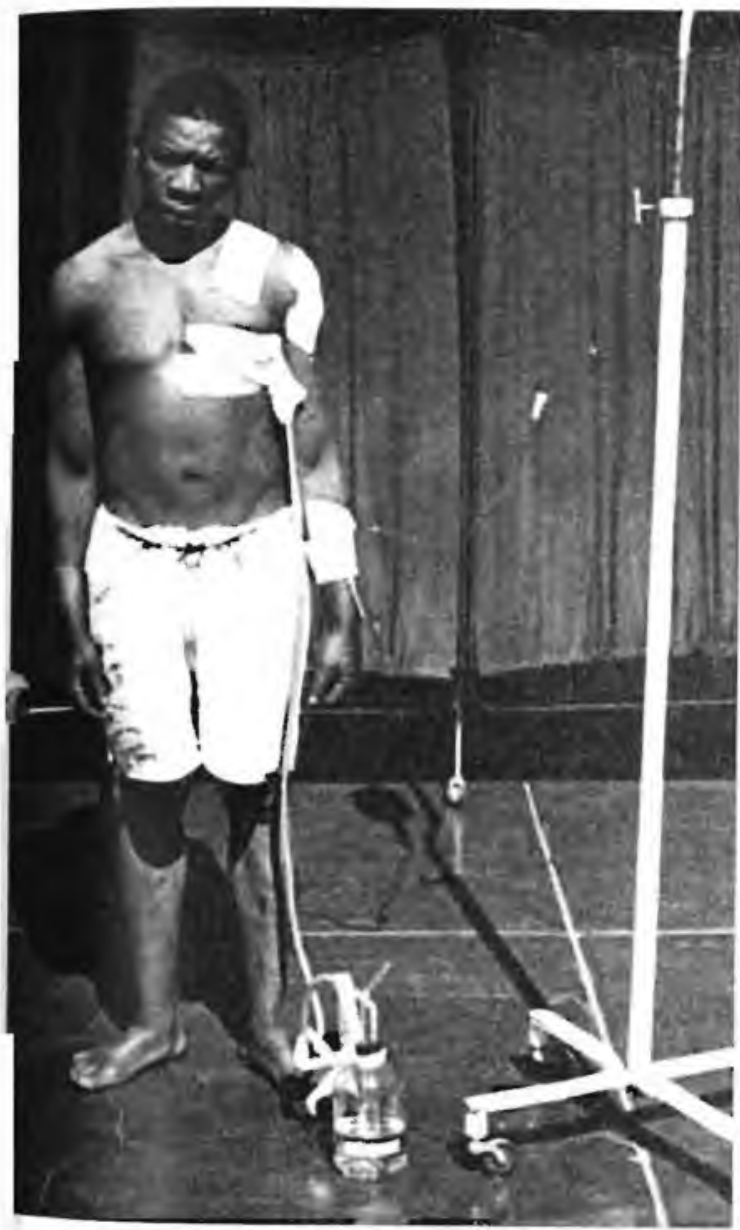

this traumatic injury to be pushed to their maximum.

(2) Although the patients are encumbered with a drip (which is always on a mobile drip stand) and an underwater drainage bottle, this is no reason for the patient not to be out of bed and being able to perform the routine set out below quite adequately.

It is only necessary that the patient realises that at all times during the treatment he must be within a safe distance from the drip stand and bottle in order that he does not pull the drip or dran out and also that he does not fall over the drip stand or bottle during his active excreises.

These patients adapt very quickly to the circumstances and no problens are normally encountered.

Figure 2. Shows paticnt with mobile drip stand and underwater drain bottle with carrying strap.

\section{SPECIFIC ROUTINE ADOPTED FOR EACH PATIENT IN TREATED GROUP}

The first treatment lasts one half hour ( $\frac{1}{2}$ hour) which in followed by a half hour rest and then followed by a further half hour treatment.

TABLE OF EXERCISES: (In order as given).

I. Sitting: Unilatera! lateral costal breathing, posterior basal breathing (unilateral), bilateral lateral costal breathing.

2. Sitting; Correct any postural deformity present.

3. Sitting; Stretch arms above head combined with inspiration and then bend trunk forwards and touch the floor with both hands combined with expiration - x 15 .

4. Sitting: Arms at sides, side flexion of trunk to both sides so that hand touches floor on that side $-\times 8$ to each side.

5. Sitting; Arms bend, right elbow moves to touch left knee and then vice versa - x 16 .

6. Standing; Running on the spot with knees up high and a fast tempo - for \pm 2 minutes.

7. Standing; Jumping to feet astride position and then together again with arms clapping above head and then down at sides for \pm 2 minutes.

8. Sitting; Coughing.

9. Standing; Arms stretch above head, inspiration and then trunk flexion so that hands touch the floor whilst patient exhales $-\mathrm{x} 10$.

10. Sitting; Blowing up approximately 6 balloons.

11. Sitting: Hands clasped in front, stretch up above head then put hands behind neck keeping elbows well back to up above head again and down $-\times 8$.

12. Sitting: Coughing.

13. Sitting; Deep breathing - blowing at tissues/ streamers moving them further away each time so that it is necessary to blow harder each time $-\times 8$. 
14. Standing; Running on the spot for 2 minutes.

15. Standing; Squats, i.e. knees bend to full flexion and then extension $-\times 15$.

16. Jumping; (Same as exercise 7) for 2 minutes.

17. Standing; Feet astride; arms yard, bend and touch right foot with left arm and then return to starting position and vice versa, i.e. left arm to touch right foot $-\times 16$.

18. Sitting; Coughing.

19. Sitting; Arms reach - loose arm and trunk swinging.

20. Blowing up 6 balloons.

The patient is then put back to bed for a half hour rest. This is followed by a second treatment of exactly the same as the first treatment, i.e. the above table of exercises.

The third treatment is given the following morning (i.e. $\pm 12-18$ hours later) and consists of the above routine, except they are done more vigorously, and performed more times at a faster tempo. At this stage, the patients with intercostal drains are treated together, in a class.

The treatments are continued twice daily until the discharge of the patient.

\section{SUMMARY:}

Reference has been made to a short survey which compared two groups of patients admitted to hospital with stabbed chests. The results of this survey indicated a beneficial result in those patients receiving eary physiotherapy. The aims of the physiotherapy and suggested format is presented for use in patients with stabbed chests complicated by haemopneumothoraces.

\section{REFERENCES}

I. J. M. HAYSE GREGSON. "Treatment of Penetrating Wounds of the Chest."

2. J. CLARK. Personal communication-as a survey on Stabbed Chests lost.

3. H. D. ADAMS. 1961 Surg. Clin. N. Amer. 41619.

4. A. STEIN. 1965 S.A. Med. Jour. 24548.

5. G. R. CRAWSHOW. 1952 S.A. Med. Jour. 26499.

6. GUYTON. Textbook of Physiology.

7. $L A S T$. Anatomy - Regional and Applied.

8. RABINOWITZ. Review of 304 cases 1972 Surgical Congress Paper.

9. A STEIN, 1967 Journal of Trauma.

10. Grant's Method of Anatomy - 8th Edition.

11. Grant's Atlas of Anatomy.

\section{POST GRADUATE COURSE}

MANIPULATION OF THE SPINE, 1974

Australian Physiotherapy Association

The next twelve-week full-time course will be conducted in Adelaide from September 30 to December 21 , 1974 if sufficient surtable applications are received. This course has been carefully designed to provide an advanced training in manipulative techniques and their application in treatment. Lectures covering anatomy, physiology, pathology, radiology, and examination procedures will be given by competent medical lecturers. Techniques and clinical application will bf taught and supervised by physiotherapists and a physical medicine specialist. The course is open to all members of tl' South African Physiotherapy Association but preference will be given to those who have had more than one year of experience. Participants will be expected to sit for examinations at the completion of the course. Cost for each successful applicant will be $\$ A 650$.

Prospectus and application forms are available from:

The Course Secretary,

Australian Physiotherapy Association (South Australian Branch) Inc.,

175 Ward Street.

North Adelaide,

South Australia, 5006.

Completed application forms with enclosures must reach the Secretary by May 11, 1974. 